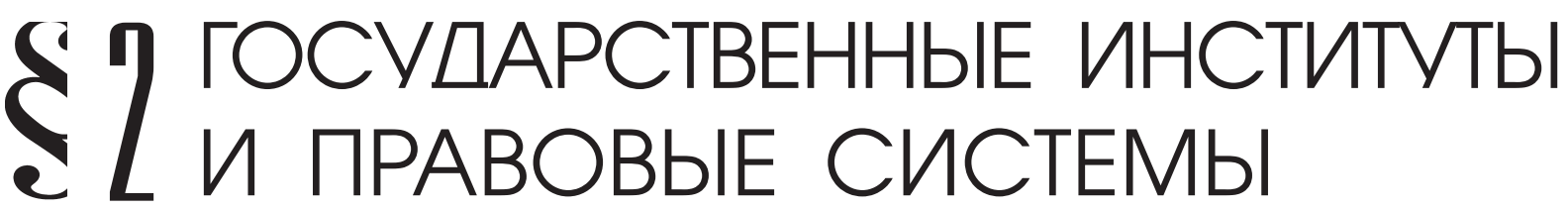

Андреев С.В.

\section{ПРАВОВЫЕ ОСНОВЫ ВЗАИМОДЕЙСТВИЯ ОРГАНОВ ГОСУДАРСТВЕННОЙ ВЛАСТИ СУБЪЕКТОВ РФ И ОРГАНОВ МЕСТНОГО САМОУПРАВЛЕНИЯ В СФЕРЕ ОРГАНИЗАЦИИ ТРАНСПОРТНОГО ОБСЛУЖИВАНИЯ НАСЕЛЕНИЯ}

Аннотация: Предметом исследования являются законодательные нормы, регулирующче транспортное обслуживание населения и устанавливающие необходимость взаимодействия органов государственной власти субъектов РФ и органов местного самоуправления в этой сфере общественно полезной деятельности. При этом основное внимание уделяется их совместной деятельности в сфере организации перевозок пассажиров автобусами, как наиболее доступного для населения вида общественного транспорта. Проблематика статьи относится к числу неразработанных в юридической литературе. Новизна содержстся и в предложениях по совершенствованию правового регулирования их деятельности в этой общественно значимой сфере. В процессе проведенного исследования использовались широко апробированный общенаучный метод диалектикоматериалистического познания, а также системно-структурный метод, метод анализа законов и иных нормативных правовых актов, формально-логический метод. В совокупности названные методы составили методологию настоящего исследования. Элементами новизны обладают определения понятий «взаимодействие органов государственной власти субъектов Российской Федерации и органов местного самоуправления» и «организация транспортного обслуживания населения», а также характеристика сути взаимодействия органов государственной власти субъектов РФ и органов местного самоуправления по организаџии транспортного обслуживания населения.

Ключевые слова: Органы местного самоуправления, субъекты РФ, органы государственной власти, транспортное обслуживание населения, транспортная стратегия, региональное законодательство, федералный закон, Конституция РФ, публичные органь, взаимодейтсвие.

Abstract: The subject of this article is the legislation governing the transport service of the population and the need for establishing cooperation between state authorities of the RF subjects and local authorities in the field of socially useful activity. With a focus on their joint activities in the sphere of transport of passengers by bus is the most accessible to the public form of public transport. In the process of the study were used widely tested scientific methods of dialectical materialist knowledge, as well as the system-structural method, the analysis of the laws and other legal acts, formallogical method. Collectively called the method was the methodology of this study.Problems article is among undeveloped in the legal literature. In this connection, the elements of novelty have definitions of "the interaction of state power of subjects of the Russian Federation and local self-government" and "the organization of transport services", as well as the characterization of the essence of the interaction of bodies of state power of subjects of the Russian Federation and local self-government for the organization of public transport services. The novelty is contained in the proposals on improvement of legal regulation of their activities in this socially important sector.

Keywords: Public authority, Constitution of the Russian Federation, Federal law, Transit strategy, Regional legislation, Mass transit, Government branches, Constituents of the Russian Federation, local self-governance, Cooperation.

Транспортной стратегии Российской Федерации на период 2030 года отмечается необходимость улучшения правового регулирования деятельности общественного транспорта на региональном и муниципальном уровнях (Собрание законодательства РФ. 2008. №50. Cm. 5977). Данная социальная потребность отражена и в Федеральной целевой программе «О повышении безопасности дорожного движения в 2013 - 2020 годах» (Собрание законодательства РФ. 2013. №41). Достижение этой цели, прежде всего, предполагает формирование четкого представления о существующей правовой основе 


\section{Право и политика $12(192) \cdot 2015$}

деятельности государственной власти субъектов РФ и органов местного самоуправления и правовом механизме их функционирования в процессе организации транспортного обслуживания населения. Под таковой, по нашему мнению, следует понимать целенаправленную деятельность региональных и муниципальных публичных органов власти по созданию комфортных и безопасных условий для перемещения (перевозки) людей транспортом общего пользования по региональным, межмуниципальным и муниципальным маршрутам к заранее определенным остановочным пунктам, станциям и вокзалам в соответствии с утвержденным расписанием его движения.

Наиболее доступным видом общественного транспорта для таких перевозок являются автобусы. В масштабах страны на их долю приходится 57,7\% перевозок пассажиров. В связи с этим, вполне закономерно, что в процессе взаимодействия, органы государственной власти и местного самоуправления сосредотачивают свое внимание на организации автомобильных перевозок пассажиров. Эта деятельность является для них основным направлением совместной деятельности по организации транспортного обслуживания населения.

Полномочия по организации транспортного обслуживания населения автомобильным транспортом отнесены к компетенции органов государственной власти субъектов РФ пунктом 12 части 2 статьи 26.3 Федерального закона от 6 октября 1999 года №184-Ф3 «Об общих принципах организации законодательных (представительных) и исполнительных органов государственной власти субъектов Российской Федерации» (далее-Федеральный закон от 6 октября 1999 года №184-Ф3) (Собрание законодательства $P Ф$. 19992. № 42. Сm. 5005). В названной правовой норме указанного Закона к полномочиям органов государственной власти отнесены также организация транспортного обслуживания населения воздушным, водным транспортом, железнодорожным транспортом в пригородном сообщении. Однако, в этих направлениях органы государственной власти действуют без участия органов местного самоуправления.

Организацией транспортного обслуживания населения в городах, муниципальных районах и других муниципальных образованиях призваны заниматься органы местного самоуправления. В статьях 14, 15, 16 Федерального закона от 6 октября 2003 года №131Ф3 «Об общих принципах организации местного самоуправления в Российской Федерации» (далее Федеральный закон от 6 октября 2003 года №131-Ф3) (Собрание законодательства РФ. 2003 г. № 40. Сm. $3822)$ в круг вопросов соответственно городских посе- лений, муниципальных районов и городских округов включен вопрос «организация транспортного обслуживания населения». При этом законодатель не конкретизирует какие виды транспорта привлекаются для обслуживания населения. Но учитывая территорию муниципальных образований, можно утверждать, что такое обслуживание, в основном, ограничивается автомобильным общественным транспортом и легковым такси. Этот вывод подтверждает и практика перевозки пассажиров.

Организация транспортного обслуживания населения автомобильным общественным транспортом, включая легковое такси, является сложной, многоаспектной деятельностью органов государственной власти и органов местного самоуправления. Ее целью является обеспечение комфортных, своевременных и безопасных условий пассажирских перевозок автобусами по вышеназванным регулярным автодорожным маршрутам. Для того, чтобы достичь эту цель необходимо в надлежащем состоянии поддерживать автомобильные дороги, произвести их разметку, установить дорожные знаки, обеспечить безопасность движения автобусов и других транспортных средств. Поэтому, на наш взгляд, имеются основания для того, чтобы организацию автотранспортного обслуживания населения характеризовать как вид комплексной деятельности. Однако, в части 2 статьи 26.3 Федерального закона от 6 октября 1999 года №184-Ф3 понятие «комплексная деятельность» не используется. Тем не менее, федеральный законодатель создал правовые условия как для деятельности органов государственной власти субъектов РФ по организации автотранспортного обслуживания населения, так и для деятельности органов местного самоуправления в этом направлении. Такое совпадение сфер деятельности органов государственной власти субъектов РФ и органов местного самоуправления является объективной причиной для их взаимодействия в процессе организации перевозок пассажиров по регулярным маршрутам на региональных и местных дорогах.

Следует отметить, что в научной литературе вопросы взаимодействия органов государственной власти субъектов РФ и органов местного самоуправления разрабатываются в общем плане, то есть без показа его специфики применительно к конкретным направлениям их деятельности. При этом анализ соответствующих научных работ показывает отсутствие общепризнанного понятия «взаимодействие органов государственной власти субъектов РФ и органов местного самоуправления», что, естественно, усложняет разработку данного понятия применительно к видам сотрудничества региональных и муниципальных 


\section{Государственные институты и правовые системы}

публичных органов власти по конкретным направлениям социально полезной деятельности.

Под взаимодействием органов исполнительной власти субъектов РФ и органов местного самоуправления О.А. Сомова, к примеру, понимает их взаимную связь, которая обусловлена самостоятельностью сторон, в пределах установленных действующим федеральным законодательством. [1, 12] Нам представляется такое общетеоретическое определение данного понятия некорректным, так как слово «связь» вряд ли применима для характеристики всего объема взаимоотношений между органами государственной власти субъектов РФ и органами местного самоуправления.

Представляется не точной и позиция С.Р. Зарипова, который считает, что взаимодействие органов государственной власти и местного самоуправления может быть обязательным, императивно предусмотренным в законе или добровольным, основанным на свободном волеизъявлении субъектов взаимодействия $[2,10]$. На наш взгляд, такой дуализм не свойственен для взаимодействия. Особенностью взаимодействия является его функционирование на принципах равноправия, согласованности и взаимной заинтересованности. Деятельность, влекущая за собой подчиненность и подконтрольность, не может быть отнесена к признакам взаимодействия.

Взаимодействие возможно только в условиях свободы волеизъявления органов публичной власти. Поэтому мы не разделяем и позицию Г.Ф. Скрипкина, который полагает, что взаимодействием охватывается и наделение органов местного самоуправления отдельными государственными полномочиями, и заключение договоров. [3, 119-120] Ведь в тех случаях, когда органам местного самоуправления передаются отдельные государственные полномочия, между ними и соответствующими органами государственной власти возникают отношения подконтрольности и подотчетности, что как отмечалось выше, не свойственно для взаимодействия.

В связи с этим мы полагаем заслуживающим внимания мнение Л.Т. Чихладзе, который считает, что делегирование государственных полномочий органам местного самоуправления деформирует местное самоуправление в сторону государственных институтов власти $[4,38]$.

По нашему мнению, под взаимодействием органов государственной власти субъектов РФ и местного самоуправления понимается вид публичного управления, осуществляемого в процессе их согласованного взаимодействия на управляемые субъекты, на основе принципов равноправия, обоюдной заинтересованности и согласованности. Предложенное понимание вза- имодействия органов публичной власти охватывает их взаимодействие в сфере организации транспортного обслуживания населения путём организационноправового взаимодействия на юридических лиц и индивидуальных предпринимателей, осуществляющих перевозки пассажиров автобусами по региональным, межмуниципальным и муниципальным маршрутам.

Предлагаемое нами определение вытекает из понятия о сущности государственного и муниципального управления как разновидности публичного управления. Под таковым понимаются общественные отношения, складывающиеся в процессе воздействия органов и должностных лиц государственной и муниципальной власти на деятельность населения, в определяемых этими органами и лицами целях и корректируемых с учётом обратной связи населения с управляющими. [5, 17-18]

Взаимодействие названных органов публичной власти в рассматриваемой сфере имеет прочную политико-правовую основу. Его укреплению способствует то, что они являются звеньями единой общероссийской публичной власти, опираются на общие конституционно-правовые принципы. Потребность в их взаимодействии обусловлена общей целью совместной деятельности, едиными нормативными методами воздействия на перевозчиков пассажиров транспорта общего пользования.

Деятельностью по организации транспортного обслуживания населения не может ограничиваться территорией муниципального образования и должна определяться потребностями населения всего субъекта РФ. От движения автобусов по региональным маршрутам во многом зависит перевозка пассажиров по муниципальными и межмуниципальным маршрутам. Поэтому желательно организацию транспортного обслуживания отнести к комплексным видам деятельности, которая осуществляется совместными усилиями органов местного самоуправления и органов государственной власти субъектов РФ. Для того чтобы последние активно и на законных основаниях участвовали в этой деятельности на уровне муниципальных образований она не должна относиться к вопросам местного значения. Такие вопросы, как установлено в Федеральном законе от 6 октября 2003 года №131-Ф3 органы местного самоуправления должны решать самостоятельно.

Для устранения существующей правовой коллизии и объективной потребности в сотрудничестве органов публичной власти, на наш взгляд, целесообразно ввести в Федеральные законы от 6 октября 1999 года №184Ф3 и от 6 октября 2003 года №131-Ф3 понятие «вопросы совместного ведения органов местного самоуправле- 


\section{Право и политика $12(192) \cdot 2015$}

ния и органов государственной власти субъектов РФ». Эти вопросы могут быть сформулированы, к примеру, путем изъятия из перечня вопросов местного значения вопроса об организации транспортного обслуживания населения. В перечне вопросов совместного ведения можно было бы также включить органам местного самоуправления и органам государственной власти субъектов РФ дорожную деятельность и другие вопросы, которые целесообразно решать совместными усилиями. В рассматриваемой сфере это позволит проводить единую транспортную политику в масштабах соответствующих субъектов РФ, устанавливать единые тарифы на оплату автобусных перевозок, единообразно решать вопросы предоставления транспортных льгот отдельным категориям населения, объединять материальные, финансовые и кадровые ресурсы. Такой подход к организации транспортного обслуживания существенно повысит качество автобусных перевозок пассажиров.

В отличии от советского периода, в современных условиях управленческая деятельность в транспортной сфере существенно расширилась за счет применения гражданско-правового метода регулирования соответствующих общественных правоотношений. В связи с этим функционирование органов государственной власти и органов местного самоуправления по решению вопросов организации транспортного обслуживания населения должно осуществляться, как уже отмечалось, на основе принципов равноправия, согласованности действий и взаимной заинтересованности, и оформляется соответствующими договорами.

В то же время анализ практики их сотрудничества показывает, что во многих субъектах РФ взаимодействие органов государственной власти и органов местного самоуправления осуществляется не на договорной основе, а на основе специальных региональных законов. В этих законах определены цели совместной деятельности, принципы и полномочия названных выше органов. К числу таких законов относится, например, Закон Тамбовской области от 14 апреля 1998 года №9-3 «О взаимодействии органов государственной власти и органов местного самоуправления Тамбовской области». Он принят в целях эффективного решения вопросов государственного и местного значения, управления процессами экономического и социального развития области и муниципальных образований в интересах населения. К основным принципам взаимодействия органов государственной власти и органов местного самоуправления Тамбовский областной законодатель отнес следующие принципы:
- сочетания интересов населения области и соответствующего муниципального образования, учета исторических и местных традиций;

- самостоятельности органов местного самоуправления в пределах их полномочий;

- взаимного согласия органов государственной власти и органов местного самоуправления при осуществлении вопросов, требующих совместного решения;

- обеспеченности финансовыми и материальными ресурсами деятельности по осуществлению вопросов, требующих совместного решения;

- добровольности заключения договоров и соглашений;

- законности, гласности и взаимной ответственности.

Названный Закон требует, чтобы органы государственной власти Тамбовской области создали необходимые правовые, организационные и материально-финансовые условия для становления и развития местного самоуправления, содействовали населению в осуществлении права на местное самоуправление, способствовали обеспечению гарантий осуществления органами местного самоуправления своих полномочий по решению вопросов местного значения, принимали программы поддержки местного самоуправления, создавали и развивали систему подготовки и повышения квалификации муниципальных служащих.

Для совместного решения социально-экономических вопросов данным Законом установлено, что органы государственной власти и органы местного самоуправления Тамбовской области наделены правом заключать между собой договоры и соглашения, а также взаимодействовать в сфере межбюджетных отношений. Представляется, что данный закон является надежной правовой гарантией для взаимодействия органов публичной власти, в том числе и в сфере организации транспортного обслуживания населения.

Взаимодействие органов государственной власти субъектов РФ и органов местного самоуправления требует объединения имущественных, финансовых и кадровых ресурсов. Однако, на этом пути имеются определенные препятствия. Они появляются в связи с отсутствием единой системы органов местного самоуправления, что влечет за собой сложности в оформлении договорных отношений между ними и органами государственной власти. Очевидно, что заключение уполномоченным государственным органом исполнительной власти субъекта РФ договора о взаимодействии в сфере организации транспортного обслуживания населения с каждым муниципальным образованием, находящимся на его территории за- 
труднительно. Ведь на территории субъектов РФ нередко находятся сотни муниципальных образований. Поэтому вряд ли целесообразно заключать такое большое количество договоров. Такая практика приводит к распылению средств и невозможности организовать контроль за исполнением договоров. Но это не означает, что следует отказаться от поиска объединения усилий органов местного самоуправления и органов государственной власти субъектов РФ. Представляется, что решению этой задачи может способствовать повышение роли советов муниципальных образований субъектов РФ, которые аккумулируют и представляют интересы всех органов местного самоуправления, входящих в эти общественные объединения.

В Федеральном законе от 6 октября 2003 года №131-Ф3 предусмотрена возможность принятия субъектами РФ законов, в которых должны определяться полномочия органов государственной власти субъектов РФ по взаимодействию с региональными советами муниципальных образований. И эту возможность широко используют субъекты РФ. Такие законы приняты, к примеру, Рязанской областью и Московской областью.

Так, согласно закону Московской области от 24 декабря 2010 года №180/2010-03 «О полномочиях органов государственной власти Московской области по взаимодействию с Ассоциацией «Совет муниципальных образований Московской области». Московская областная Дума и исполнительные органы государственной власти Московской области в процессе взаимодействия с областным Советом муниципальных образований вправе привлекать представителей Совета для обсуждения проектов областных законов и других нормативных правовых актов, для участия в семинарах и конференциях и иных мероприятиях по вопросам местного самоуправления, обмениваться с Советом статистическими, аналитическими и иными материалами, представляющими общий интерес, а также заслушивать ежегодный доклад Совета о развитии местного самоуправления на территории Московской области. В свою очередь представители органов государственной власти Подмосковья вправе присутствовать на заседаниях областного Совета муниципальных образований. Повышению его значимости способствует представление права законодательной инициативы в областной парламент.

В целом, данный Закон Московской области создал довольно прочную региональную правовую базу для сотрудничества органов государственной власти с Советом муниципальных образований. Подобная практика имеется и в других субъектах РФ.

Советы муниципальных образований имеют возможность влиять на содержание регионального нормативного процесса, инициировать принятие нормативных правовых актов, регулирующих общественные отношения, возникающие при перевозках пассажиров автомобильным транспортом. Дальнейшему повышению роли советов муниципальных образований субъектов РФ способствовало бы, на наш взгляд, наделение их полномочиями по координации органов местного самоуправления городских поселений, муниципальных районов и городских округов и по представлению их интересов во взаимоотношениях с органами государственной власти субъектов РФ. При этом, советы муниципальных образований по поручению соответствующих органов местного самоуправления могли бы заключать от их имени договоры с уполномоченными органами государственной власти для объединения усилий при строительстве и реконструкции местных и региональных автомобильных дорог, организации транспортного обслуживания населения, а также обобщать итоги их исполнения. Такие полномочия Советов следовало бы закрепить в Федеральном законе от 6 октября 2003 года №131-Ф3.

Таким образом, дальнейшее укрепление взаимодействия органов государственной власти субъектов РФ и органов местного самоуправления видится в совершенствовании правового регулирования их совместной деятельности, в развитии организационно-правового механизма сотрудничества на основе договоров. Гарантией решения стоящих перед названными публичными органами задач в исследуемой сфере является их нахождение в едином политическом, социально-экономическом и территориальном пространстве.

\section{Библиография:}

1. Сомова О.А. Правовые основы взаимодействия органов государственной власти субъектов Российской Федерации и органов местного самоуправления. Автореф. дисс. ... канд. юрид. наук. Саратов. 2003.

2. Зарипов С.Г. Нормативное правовое регулирование взаимодействия органов государственной власти и органов местного самоуправления субъектов Российской Федерации (на примере Республики Татарстан). Автореф. дисс. ... канд. юрид. наук. Казань. 2012.

3. Скрипнин Г.Ф. Взаимодействие органов государственной власти и местного самоуправления. М., 2011.

4. Чихладзе Л.Т. Взаимодействие органов государственной власти и органов местного самоуправления: Теория и современная практика. Сергиев Посад. 2009.

5. Чиркин В. Е. Государственное и муниципальное управление. М., 2003. 
DOI: $10.7256 / 1811-9018.2015 .12 .16769$

При цитировании этой статьи сноска на dоі обязательна

Право и политика $12(192) \cdot 2015$

\section{References (transliterated):}

1. Somova O.A. Pravovye osnovy vzaimodeistviya organov gosudarstvennoi vlasti sub"ektov Rossiiskoi Federatsii i organov mestnogo samoupravleniya. Avtoref. diss. ... kand. yurid. nauk. Saratov. 2003.

2. Zaripov S.G. Normativnoe pravovoe regulirovanie vzaimodeistviya organov gosudarstvennoi vlasti i organov mestnogo samoupravleniya sub"ektov Rossiiskoi Federatsii (na primere Respubliki Tatarstan). Avtoref. diss. ... kand. yurid. nauk. Kazan'. 2012.

3. Skripnin G.F. Vzaimodeistvie organov gosudarstvennoi vlasti i mestnogo samoupravleniya. M., 2011.

4. Chikhladze L.T. Vzaimodeistvie organov gosudarstvennoi vlasti i organov mestnogo samoupravleniya: Teoriya i sovremennaya praktika. Sergiev Posad. 2009.

5. Chirkin V. E. Gosudarstvennoe i munitsipal'noe upravlenie. M., 2003. 